\title{
CONSTRAINTS ON THE PRECISION OF SAR IN EQUIVALENT DOSE ESTIMATIONS CLOSE TO SATURATION IN QUARTZ
}

\author{
CONSTANTIN ATHANASSAS \\ Laboratory of Archaeometry, Institute of Materials Science, N.C.S.R. 'Demokritos', \\ Aghia Paraskevi, 153 10, Athens, Greece
}

Received 30 June 2010

Accepted 4 April 2011

\begin{abstract}
Difficulties in evaluating accurate equivalent doses for Late Quaternary sediments from the south coasts of Greece arose in the course of SAR measurements. Large scatter among apparent equivalent doses perplexed the evaluation of accurate mean estimates in circumstances where very large doses were involved. Besides, dose recovery experiments revealed that when intersection of the natural signal occurs onto the saturating segment of the growth curve, a distinct relationship between $D_{e}$ and growth curve shape occurs. At very low slope angles, SAR tends to overestimate the recovered dose. The mechanism which controls the spread in equivalent dose estimation is investigated.
\end{abstract}

Keywords: SAR precision, equivalent dose distributions, scatter, dose recovery, slope.

\section{INTRODUCTION}

The Single Aliquot Regenerated dose protocol (SAR) by Murray and Wintle (2000) has been broadly accepted as a method for determining the palaeodose (or the equivalent dose) of quartz in the Optically Stimulated Luminescence (OSL) dating of sediments. Its introduction to the luminescence community gave rise to a boom of chronologies within the last decade, pushing forward our understating of the Late Quaternary.

On the other hand, saturation of the OSL trap controls the range of doses within which SAR can provide safe age estimates. This range is often associated with the linear segment of a dose response curve, where the sensitivity corrected OSL signal is proportional to the absorbed dose. In chronological terms, this secure doserange can be interpreted in the last $\sim 100 \mathrm{ka}$. This has been proposed as an average back limit in OSL dating, as derived from former studies (Murray and Olley, 2002). However, there were cases where SAR exhibited a similarly good performance in the recovery of doses which

Corresponding author: C. Athanassas

e-mail: athanassas@ims.demokritos.gr laid on the curved part of the growth curve (Murray et al., 2002; Murray et al., 2008).

Nevertheless, there have been several other efforts to measure the dose in the non-linear region which resulted in questionable precision; the higher up the growth curve the larger the error and asymmetry in the mean $D_{e}$ (Murray and Funder, 2003; Kim et al., 2010). A possible explanation has been speculated by Murray and Funder (2003), who attributed the enlargement in uncertainty to the sub-linearity that describes the relationship between dose and the responding sensitivity corrected OSL signal. Error bars which come with the instrumental record of the luminescence intensity will magnify on the dose-axis, after they are projected onto the exponentially saturating growth curve. More lately, Wintle and Murray (2006), in a review of the SAR attainments in the OSL dating of quartz, support that the trend in $\mathrm{D}_{\mathrm{e}}$ seen by Murray and Funder (2003) can be dealt with if only equivalent doses smaller than twice the characteristic dose $\left(D_{e}<2 D_{0}\right)$ are taken into account in growth curves leaning to saturation. Thus, the shifting point from linearity to sub-linearity in a dose response curve of quartz may be a threshold, beyond which age estimations should be dealt with caution. 
In this study, the performance of SAR is tested on quartz from coastal samples from the southwest beaches of Greece. Paepe et al. (1990) have assumed a Last Interglacial age for those samples or perhaps older $(\geq \sim 125 \mathrm{ka})$. The large size of the assumed equivalent dose will therefore challenge SAR's validation. Truly, equivalent dose distributions from Greek samples (Fig. 1a) display large span and skewness. Probability density functions (Fig. 1b), make evident positive skewness in the dataset, whilst cumulative probability density plots intimate deviance of the $\mathrm{D}_{\mathrm{e}}$ distribution from the concept of normal for estimates larger than $100 \mathrm{~Gy}$. The associated uncertainty $(37 \%)$ complicates the assessment of a secure average $D_{e}$. Provided that these sediments received adequate bleaching before deposition and were buried in a homogeneously radiating environment, such distributions doubt the ability of SAR to produce accurate $D_{e}$ estimates for very old samples.

Were the observed uncertainty attributed to systematic failures of SAR when natural OSL is close to saturation, conventional statistical methods could not easily assess the standard deviation in $\mathrm{D}_{\mathrm{e}}$ (Duller, 2007). To simply average the histogram of Fig. 1 will be misleading in dating implications. The mechanism which leads to this perplexity is for that reason essential to be examined. Although, problems related to scatter in $\mathrm{D}_{\mathrm{e}}$ due to saturation can now universally be tackled by the condition introduced by Wintle and Murray (2006), this paper not only targets to tighten already calculated $\mathrm{D}_{\mathrm{e}}$ distributions using the available means, but also to deepen into the causes generating the scatter observed.

Dose recovery tests are a straightforward way of adding insight to the development of spread on $\mathrm{D}_{\mathrm{e}}$ over transition from linear unto curved parts of a growth curve. An extended experiment of this kind was designed for a set of quartz aliquots of a sediment sample which was reckoned to be suitable for the SAR method. This experiment grounds this paper and aimed at watching the mode of the
OSL response following a broad range of known doses, from a few grays up to around a thousand. Besides, it allowed us to examine how the involvement of very large amounts of irradiation can make difficult the calculation of precise average $D_{e}$ estimates, and finally, to inspect whether experimental data can interpret the pattern seen in natural samples (Fig. 1). Experimental parameters, conditions and results are reported in detail further below.

\section{SAMPLE PREPARATION AND MEASURE- MENT SETTINGS}

Beachrock and fossil dune samples were collected from the southwestern coast of Greece They are assumed to reflect specific depositional palaeo-environments, where complete sunlight bleaching can be guaranteed. Pure quartz was obtained by practicing the typical chemical process $\left(10 \% \mathrm{HCl}, 20 \% \mathrm{H}_{2} \mathrm{O}_{2}\right.$, first sieving, density separation, $\mathrm{HF}$, second sieving).

Medium sized aliquots (5 $\mathrm{mm}$ in diameter) containing 90-125 $\mu \mathrm{m}$ quartz grains were used in the measurements. The unit used for luminescence measurements was a RIS $\varnothing$ TL-DA-15 reader. An EMI 9635Q photomultiplier and two $3 \mathrm{~mm}$ Hoya U-340 filters were attached on the system. The device was also supplied with a ${ }^{90} \mathrm{Sr} /{ }^{90} \mathrm{Y}$ beta source for automated irradiations, delivering $6.5 \mathrm{~Gy} \mathrm{~min}^{-1}$. In order to estimate the intensity of the sensitivity-corrected OSL, SAR was used in its original form, as it has been introduced by Murray and Wintle (2000). Recordings of the natural and regenerated fast and medium OSL signal components were made by stimulations with blue LEDs at $125^{\circ} \mathrm{C}$ for $40 \mathrm{sec}$, applied soon after a preheat $(\mathrm{PH})$ at $220^{\circ} \mathrm{C}$ for $10 \mathrm{sec}$. Administration of the test dose in the following step was succeeded by a second $\mathrm{PH}$ (cut heat) at $160^{\circ} \mathrm{C}$, holding the sample for zero time. This served as to sweep unwanted charge captured by shallow traps. Net signal intensities were calculated as the integral of the first second of measurement, subtracted by that of the last 8 seconds.
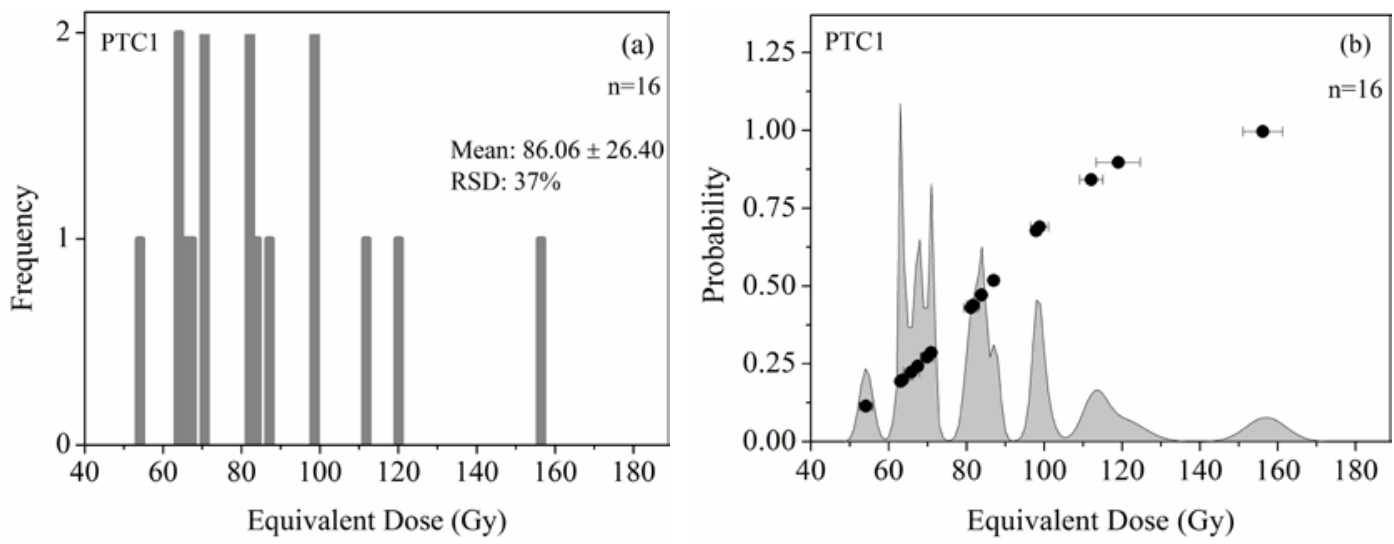

Fig. 1. (a) Histogram representing the equivalent dose distribution of a Late Quaternary fossil coastal dune from SW Greece. (b) RSD refers to related standard deviation. Bin widths have been chosen as the median of the errors on each $D_{e}$ (Lepper et al., 2000). Equivalent doses have also been plotted as a weighted histogram, by summing probability density functions (Gaussian distributions) of every single $D_{e}$, following the probability density approach of Singhvi et al. (2001). Data are additionally illustrated in the form of cumulative probability density function (dots). 
This study also included estimation of the radioelement content and the assessment of dose rates by means of $\alpha$ - and $\beta$-counting. Table 1 makes available mean equivalent doses, radionuclide concentration and dose rates for some representative samples.

\section{GENERAL PERFORMANCE}

\section{Luminescence characteristics}

Fig. 2a illustrates series of typical regenerated OSL decay curves from one quartz aliquot (sample KRN5), including also that of the natural signal. They correspond to sequential responses of 27, 49, 97194 and $389 \mathrm{~Gy}$, respectively. Each has been normalised to the first $0.16 \mathrm{sec}$ of measurement so that they are comparable. The fast OSL component is strongly distinct within the first $\mathrm{sec}$ and thus the integration limits suggested earlier are correct.

All decay curves decay in an identical manner, intimating constant proportionality among the three signal components (the other two are the medium and slow) throughout the sequence. A test dose of $27 \mathrm{~Gy}$ was set in between succeeding regenerating irradiations. Its response at each cycle is seen in Fig. 2b. Again, coincidence is seen among signal components and a similar explanation can be reckoned. The sensitivity corrected OSL response, standardised by the test dose (Roberts and Duller, 2004), is shown in Fig. 2c. Growth curve fitting for all aliquots included here was executed by Analyst software (Duller, 2001). Analyst automatically fits the best matching curve to a series of regenerated doses per aliquot. Employment of saturating exponentials including a linear constituent (ExpLin) has resulted here in fitting errors smaller than average induced by single saturating exponentials, particularly for the highdose part of the growth curve. The generalised mathematical expression for ExpLin fittings, as performed by the Analyst, is shown below (Eq. 3.1), where $y$ is the corrected OSL signal intensity following a dose $x, a$ is the infinite value that OSL signal reaches at saturation, $b$ is the characteristic dose that describes the onset of saturation, $c$ regulates the size of any initial offset of OSL from zero and $g$ determines the slope of the linear component. ExpLin fittings stood valid for all aliquots involved in the measurements. Any error in fitting is incorporated in the error on every single $D_{e}$.
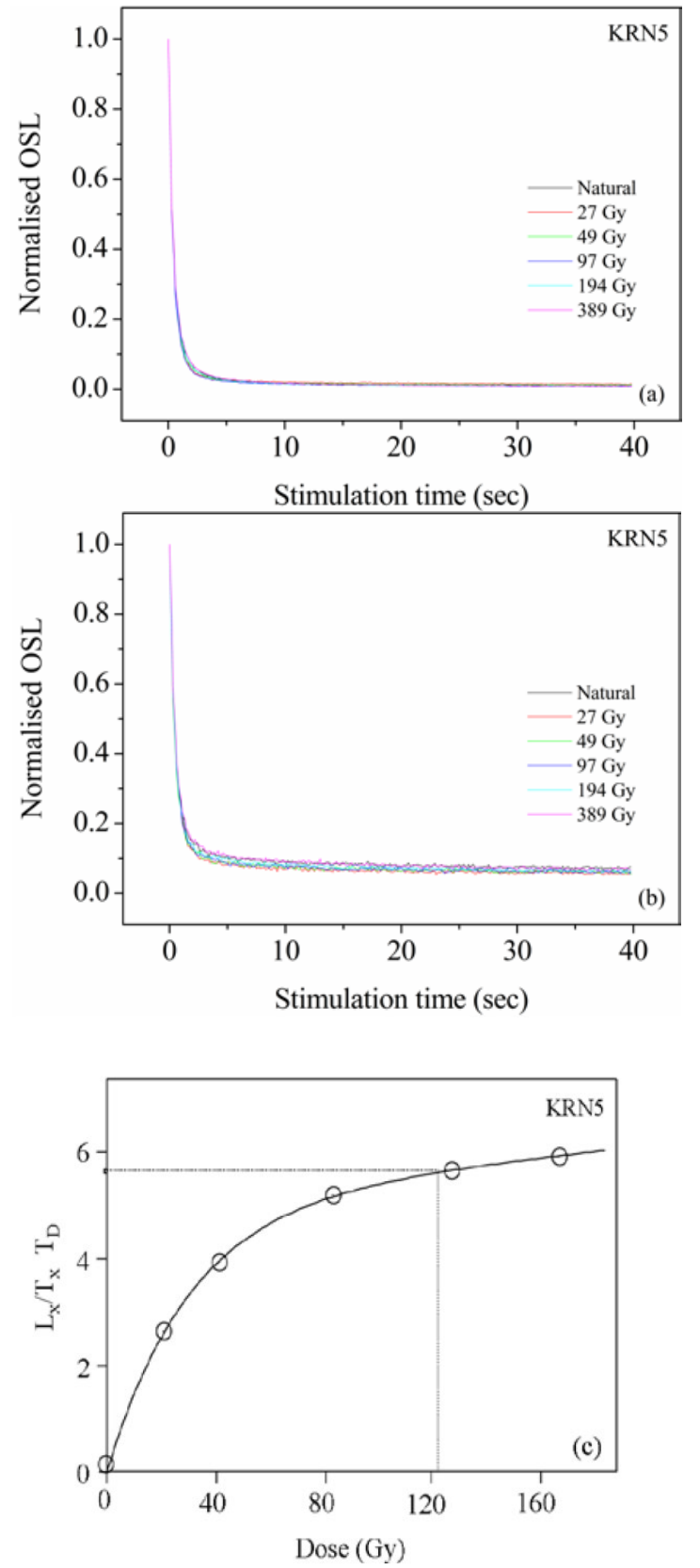

Fig. 2. Successive decay curves of a sequence of regenerated doses (a), their intermediate 5 Gy test dose (b) as well as the resulting growth curve (c).

Table 1. Initial equivalent doses, radioelement concentrations and final dose rates for some representative samples from SW Greece. $U, T h, K$ were estimated by combining $\alpha$ - and $\beta$-counting measurements. Final dose rates incorporate cosmic ray contribution and they have been corrected for grain-size (90-125 $\mu \mathrm{m}$ ) attenuation. Dose rate conversion factors are from Adamiec and Aitken (1998).

\begin{tabular}{lccccc}
\hline Sample & Equivalent dose $(G y)$ & $\mathrm{U}(\mathbf{p p m})$ & Th $(\mathrm{ppm})$ & $\mathrm{K}(\% \mathbf{w t})$ & Dose rate $(\mathrm{Gy} / \mathrm{ka})$ \\
\hline PTC1 & $86.1 \pm 26.4$ & $0.83 \pm 0.06$ & $1.13 \pm 0.17$ & $0.17 \pm 0.02$ & 0.6010 .01 \\
\hline PTC2 & $64.3 \pm 26.8$ & $0.86 \pm 0.09$ & $2.12 \pm 0.28$ & $0.18 \pm 0.02$ & $0.83 \pm 0.02$ \\
\hline KRN2 & $173.3 \pm 65.1$ & $0.65 \pm 0.07$ & $1.76 \pm 0.22$ & $0.48 \pm 0.02$ & $0.81 \pm 0.02$ \\
\hline KRN3 & $147.1 \pm 19.0$ & $0.64 \pm 0.05$ & $1.18 \pm 0.17$ & $0.21 \pm 0.02$ & $0.52 \pm 0.01$ \\
\hline KRN5 & $182.7 \pm 69.0$ & $0.61 \pm 0.04$ & $0.73 \pm 0.12$ & $0.22 \pm 0.02$ & $0.52 \pm 0.01$ \\
\hline KRN6 & $193.9 \pm 54.7$ & $0.74 \pm 0.04$ & $0.60 \pm 0.12$ & $0.07 \pm 0.01$ & $0.40 \pm 0.01$ \\
\hline
\end{tabular}


$y=a \times\left(1-e^{\frac{-x-c}{b}}\right)+g x$

The 27 Gy dose was repeated twice in order to produce a recycling point (and a recycling ratio of 0.97 ). Natural signal interpolates at the exponentially saturating segment of the growth curve, way up the linear section. Errors on the individual equivalent doses have been worked out by simply transforming the uncertainty of the $\mathrm{L}_{\mathrm{x}} / \mathrm{T}_{\mathrm{x}}$ ratios, incorporating also the uncertainty from the growth curve fitting (Duller, 2007). The validity of the equivalent dose (122 \pm 14.4 Gy) cannot be ensured at the moment, since it comes from a dose region of questionable reliability, as discussed in the beginning.

\section{Preheat tests}

A series of preheat $(\mathrm{PH})$ temperatures were applied to aliquots of the same sample and the resulting $D_{e}$ values were then plotted versus the preheat temperature. If individual equivalent doses congregate to a certain value, this constitutes a preheat plateau. The presence of a PH plateau intimates that sensitivity can be corrected appropriately during a full SAR sequence and therefore $D_{e} s$ resulting from the plateau are accurately measured. When selecting a PH temperature, scatter makes it difficult to directly observe whether there is a preheat plateau. Fig. 3a depicts a number of aliquots from a single sample which had their $\mathrm{D}_{\mathrm{e}} \mathrm{s}$ measured at different $\mathrm{PH}$ temperatures. Despite this, averaged $\mathrm{D}_{\mathrm{e}} \mathrm{s}$ (dashed line) faintly suggest a plateau from $220^{\circ} \mathrm{C}$ on. Further consolidation of SAR's credibility was therefore sought on the basis of known doses, so as to temporarily overcome perplexities arisen by the spread in the natural dose. A sum of 21 aliquots from the same group of samples had their fast and medium components artificially removed by two OSL stimulations at $125^{\circ} \mathrm{C}$ for $40 \mathrm{sec}$ (Jacobs et al.,
2006), and then were given a dose of 20 Gy. The discs were grouped in seven sets of three, and individual $\mathrm{PH}$ temperatures were selected for each group, ranging between $160-280^{\circ} \mathrm{C}$. Equivalent doses were estimated using SAR and correcting with a test dose of 17 Gy. All 21 aliquots passed the recycling ratio test (Murray and Wintle, 2000). Fig. 3b exhibits the results from the new PH test. Although the $\mathrm{D}_{\mathrm{e}}$ decreases a little from 160 to $200^{\circ} \mathrm{C}$, a preheat plateau tends to form at temperatures above $200^{\circ} \mathrm{C}$. Therefore, engagement of artificial doses supports the existence of a $\mathrm{PH}$ plateau within the same temperature range as natural doses vaguely imply. Hence, the selection of a $220^{\circ} \mathrm{C} \mathrm{PH}$, as suggested earlier, was sufficient.

\section{Sensitivity changes}

Sensitivity changes commonly occur in quartz during SAR measurements and they should always be under control. The magnitude and course of sensitivity variation largely depends on the preheat temperature. In SAR, a basic notion is that the OSL response to a test dose $\left(T_{x}\right)$ after the measurement of the luminescence of a foregoing regenerated dose $\left(L_{x}\right)$ is an actual representation of the sensitivity of the preceding regenerated OSL signal. In the view of a constant regeneration dose, the proportion of the two signals over a series of measurement cycles should also be constant, regardless of the change in sensitivity. Monitoring of sensitivity variations through repetitive measurement cycles is accomplished by plotting $T_{x}$ against the measurement cycle. Here, the mode of sensitivity change in the course of a standard SAR sequence was studied on three identical quartz aliquots by repeating 8 times a constant regeneration dose of 50 Gy and a test dose fixed at 5 Gy. A preheat temperature of $220^{\circ} \mathrm{C}$ supervened the administration of the regenerated dose, whilst a cut-heat of $160^{\circ} \mathrm{C}$ was run after the application of the test dose.
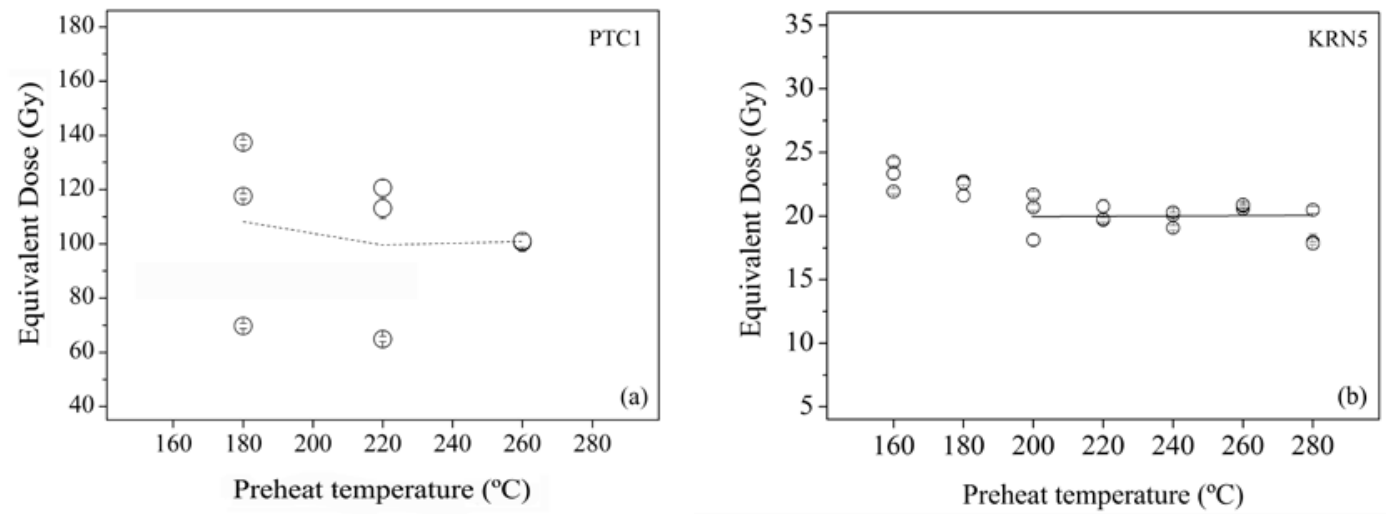

Fig. 3. Results of the PH test using natural doses (a) and artificial irradiations (b). Three aliquots were measured at each indicated temperature for both experiments. A PH plateau tends to form for temperatures over $200^{\circ} \mathrm{C}$. Data points coincide at $260^{\circ} \mathrm{C}$ in a. Error bar length is capped by the size of data point symbols. 
Fig. 4a takes account of the relative sensitivity change through regenerated cycles, this is the response of the test dose in each cycle normalised by the test dose signal of the first measurement $\left(\mathrm{T}_{\mathrm{N}}\right)$. Not only changes in sensitivity occur, but they seem to intensify with the measurement cycle, appearing increased by $20 \%$ at the end of the $8^{\text {th }}$ cycle. This fashion is similar to that following high temperature preheats (Armitage et al., 2000). Next, the proportion between $\mathrm{L}_{\mathrm{x}}$ and $\mathrm{T}_{\mathrm{x}}\left(\mathrm{L}_{\mathrm{x}} / \mathrm{T}_{\mathrm{x}}\right)$ is plotted against the measurement cycle. Fig. $\mathbf{4 b}$ makes evident that all three $\mathrm{L}_{\mathrm{x}} / \mathrm{T}_{\mathrm{x}}$ datasets converge on a certain value respectively. Bringing together data from both Fig. 4a and b we can now assert that sensitivity correction using a test dose can be realistic.

\section{Recycling Ratios}

Murray and Wintle (2000) and Wintle and Murray (2006) suggest that sensitivity correction should be checked for each aliquot involved in the measurements. This can be attained by undertaking duplicate measure-
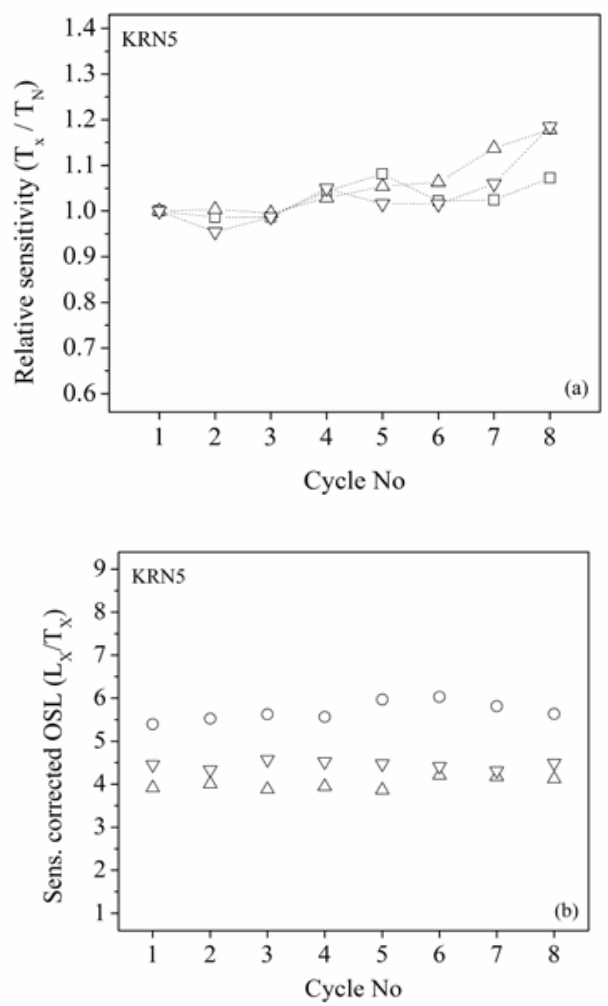

Fig. 4. Plots of relative sensitivity change and sensitivity corrected OSL responses for three aliquots. a) The OSL response of a 5 Gy test dose has been plotted versus the number of repetitions of a preceding, 50 Gy, regenerated dose OSL response $\left(L_{x}\right)$. Tx refers to the test dose OSL intensity while $T_{N}$ refers to the test dose OSL intensity of the first cycle. Data have been plotted as relative sensitivity $\left(T_{x} / T_{N}\right)$. b) $L_{x} / T_{x}$ ratios per aliquot tend to converge on a certain value in the course of cycle repetition, suggesting that sensitivity correction over a SAR sequence is attainable. ments of the same dose at the beginning and at the completion of a full SAR sequence. If the sensitivity correction is sufficient both normalised OSL intensities have to be similar and their ratio (Recycling Ratio) should be close to unity. Twelve fresh aliquots went through a complete SAR sequence and a 50 Gy dose was applied twice (start and end of the sequence, in a procedure identical to that described in Wintle and Murray, 2006). The twelve recycling ratios that were produced have been plotted as a histogram in Fig. 5. Individual aliquots succeed to perform SAR demands, with all estimates falling within $[0.9,1.1]$ and generating an average value of $0.99 \pm 0.04$. Changes in sensitivity can thereupon be kept under control on the whole. In the very seldom occasion of aliquots failing to meet the aforesaid need, associated $\mathrm{D}_{\mathrm{e}} \mathrm{s}$ were excluded from the construction of graphs and further analysis.

\section{Dose recovery}

Recovery of artificial doses is a robust means of checking the accuracy that SAR can estimate the $D_{e}$ with. Dose recovery tests should be mandatory in any dating project. In this respect, a series of dose recovery experiments were conducted here to find out what is the maximal dose that SAR can accurately recover. Eighty KRN5 aliquots were bleached as described in the preheat tests section and separated in 8 groups, each group containing 10 aliquots. Different sets of aliquots received different doses from a range between 5 and 970 Gy and underwent a full SAR. Table 2 provides information on administered doses, test doses and maximum regenerated doses utilized in the measurements.

Fig. 6a directly compares the recovered with the given doses. At $970 \mathrm{~Gy}$, the data point is represented by no

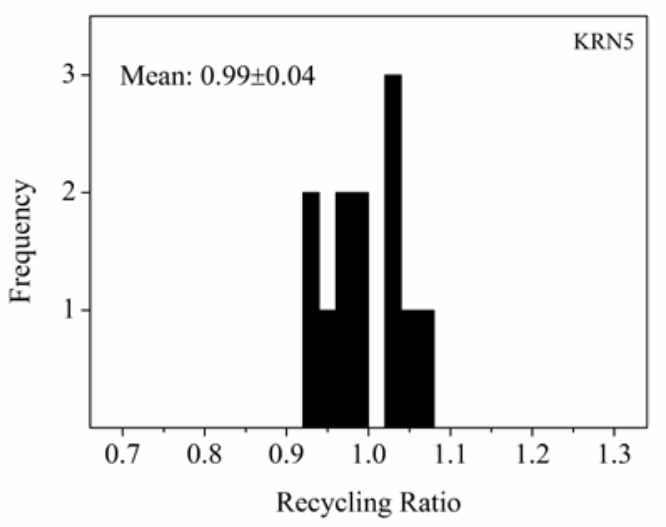

Fig. 5. Histogram of recycling ratios (RR) from $12 \mathrm{KRN5}$ aliquots. A dose of $50 \mathrm{~Gy}$ was measured twice, first immediately after the measurement of the natural signal and secondly after the completion of the sequence. The ratio of the two resulting $L_{x} / T_{x}$ ratios represents the recycling ratio. All RR fall within [0.9-1.1] as Murray and Wintle (2000) demand. 
Table 2. Given doses, test doses and maximum regenerated doses used in the dose recovery test.

\begin{tabular}{lll}
\hline Given lab dose (Gy) & Test dose (Gy) & Max. regen. dose (Gy) \\
\hline 5 & 1 & 10 \\
\hline 10 & 2 & 20 \\
\hline 20 & 2 & 40 \\
\hline 50 & 2 & 80 \\
\hline 100 & 2 & 150 \\
\hline 200 & 5 & 400 \\
\hline 500 & 5 & 1000 \\
\hline 1000 & 5 & 2000 \\
\hline
\end{tabular}

more than four aliquots, as only four $\mathrm{L}_{\mathrm{N}} / \mathrm{T}_{\mathrm{N}}$ ratios passed across the growth curve. As a consequence, the recovered mean $D_{e}$ at $970 \mathrm{~Gy}$ is known with less precision than that from smaller administered doses. Recovery is very precise below 100 Gy. Further up, severe overestimation is systematically observed, followed by a systematically increasing standard deviation. Scatter resulting from the recovery of doses larger than 100 Gy could be comparable to the scatter seen in natural samples in Fig. 1.

Two issues arise from these dose recovery results. First, to investigate the factor that controls the spread in mean $D_{e}$ at high doses, along with the systematic overestimation. Second, to examine whether the spread noticed in natural data (Fig. 1) can be attributed to a similar cause.
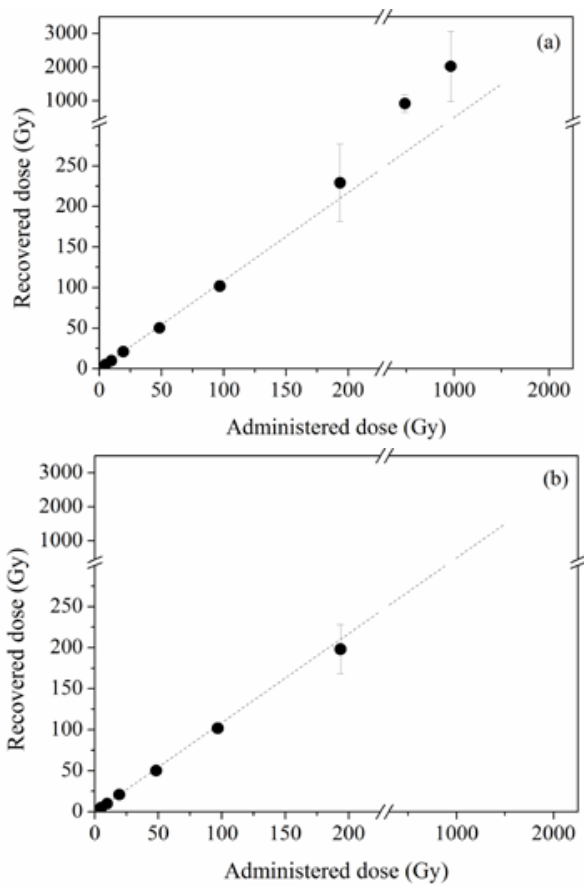

Fig. 6. Relationship between given and regained doses in comparison with the 1:1 line before (a) and after correcting for slope dependence (b), as discussed in section 4. Data point at 1000 Gy is represented by four aliquots as only those succeeded to intersect the growth curve. Note the change in scale after the break in the $X$ and $Y$ axes.

\section{DEPENDENCE OF $D_{\mathrm{e}}$ ON GROWTH CURVE SHAPE}

Fig. 7 illustrates standardised growth curves (SGC) based on the procedure elucidated by Roberts and Duller (2004). In this normalisation, growth curves obtained in the earlier dose recovery experiment have been multiplied by their respective test doses, so that they are comparable. Strong variability in luminescence response can be seen beyond $100 \mathrm{~Gy}$. In addition, distributions of the regained equivalent doses (on $\mathrm{X}$-axis), as well as distributions of their related standardised sensitivity-corrected OSL responses (on Y-axis) have been included for 50 Gy (deep grey) and 500 Gy (light grey).

In the low-dose segment, projection of normally distributed OSL signals onto the growth curve results in normally and tightly distributed $\mathrm{D}_{\mathrm{e}}$. On the other hand, at larger doses, projection of signals with similar relative spread onto the sub-linear part of the growth curve generates broad and skewed $\mathrm{D}_{\mathrm{e}}$ distribution. It thus looks that when large doses are involved, there is a relationship between growth curve shape, mode of $\mathrm{D}_{\mathrm{e}}$ distribution, and possibly scatter in inter-aliquot dose response characteristics.

A similar pattern has been predicted by Murray and Funder (2003) and it could bear resemblance to that seen in natural samples (Fig. 1). Increased inter-aliquot scatter in dose response properties among individual aliquots may also be an extra contribution to the observed spread.

Within the histogram, there are individual estimates which give the right answer; that is apparent $D_{e} s$ converging on the given dose. However, there are others which differ. Divergence from symmetry owes to these outliers which tail off and broaden the distribution at higher doses. It would therefore be interesting to investigate the factor which diversifies so much the dose recovery be-

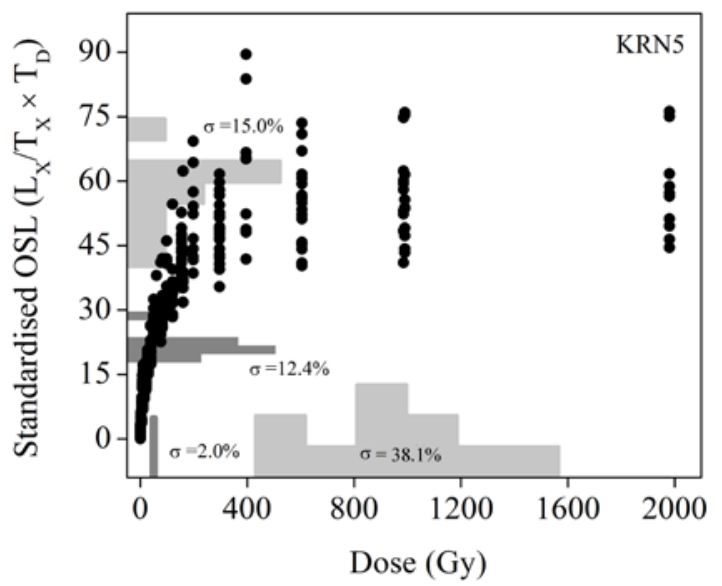

Fig. 7. Standardised growth curves, standardised OSL signal distributions as well as their respective equivalent dose distributions at $50 \mathrm{~Gy}$ (dark grey) and $500 \mathrm{~Gy}$ (light grey) dose recovery. ' $\sigma$ ' refers to the standard deviation. 
haviour of otherwise identical aliquots of quartz grains, provided that they have absorbed the same amount of radiation.

Fig. 8 illustrates a case of such two extremes. Both aliquots received 200 Gy but produced two unequal equivalent doses. In the first case (Fig. 8a) the initial signal intersects with a large growth curve slope and generates a dose precisely close to the original. To the contrary, intersection with a rather small slope in the second case (Fig. $8 \mathrm{~b})$ results in overestimated dose. Slope at any point of the growth curve is geometrically denoted by the tangential and its measure is mathematically represented by the first order derivative of the growth curve equation. Nevertheless, certain versions of the Analyst (e.g. 3.15) automatically calculate slope (i.e. $1^{\text {st }}$ order derivative) at the point where natural OSL interpolates the growth curve, releasing us from manual differentiations. All slope values provided in this paper have been calculated entirely with the Analyst.

Every single equivalent dose yielded in dose recovery experiment was plotted against its respective slope (i.e. where natural signal interpolates) in Fig. 9. At low doses $(\leq 100 \mathrm{~Gy})$ individual $\mathrm{D}_{\mathrm{e}}$ tends to be consistent with the given dose no matter what slopes are encountered. However, at higher doses some aliquots may give $D_{e}$ which depends on the slope, when the last becomes smaller than a certain value $(\sim 0.6)$. Shift in growth curve slope may thereupon be a factor for asymmetry.

The mechanism which controls the aforesaid relationship is further explored by considering the fitted mathematical equations which describe the luminescence growth. Eq. 3.2 was an example of a growth curve equation from one KRN5 aliquot used in the recovery of a 200 Gy dose.

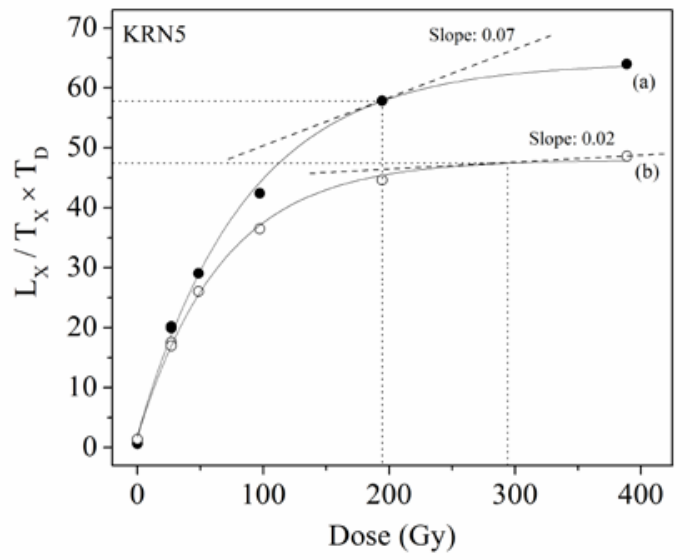

Fig. 8. Comparison between growth curves from two aliquots which were administered 200 Gy and had their OSL response regenerated up to $400 \mathrm{~Gy}$. Note the different slopes where natural signals interpolate the growth curves respectively. $y=41.7 \times\left(1-e^{\frac{-x+0.7}{53.7}}\right)+0.1 x$

In the above growth curve equation, $y$ is the standardised sensitivity corrected OSL signal as a function of the corresponding dose $x$. Parameters in Eq. 3.2, (the meaning of each one has been introduced in Eq. 3.1 and here $\mathrm{a}=41.7, \mathrm{~b}=53.7, \mathrm{c}=0.7, \mathrm{~g}=0.1$ ) have automatically been fitted by Analyst at the growth curve fitting stage and similar functions have been produced for all aliquots involved in this study. The slope angle of the tangent at each data point can be quantified by its first order derivative and it is shown in Eq. 3.3. The latter predicts that, in non-linear growth curves, dose always remains a function of slope. Fig. 10 schematically yields that pattern for a range of slope values and strikingly resembles the experimental pattern observed in Fig. 10.

$\frac{d y}{d x}=0.78 \times e^{\frac{-x+0.7}{53.7}}+0.1$

In particular, $\mathrm{D}_{\mathrm{e}}$ values resulting from high growth curve gradients exhibit small slope dependency, and given that small overestimations can also be obscured by random errors (Duller, 2007), recovered $\mathrm{D}_{\mathrm{e}}$ can be considered more or less uniform for a range of large slopes. This trend can approximate to some extent what results from the differentiation of linear growth curves and it is sufficient enough to interpret the consistencies seen in Fig. 9 at low doses. Far from that, when very low growth curve gradients are confronted, recovered $\mathrm{D}_{\mathrm{e}} \mathrm{s}$ strongly depend on the slope, resulting in extreme and systematic overestimations. The latter simulates similar results acquired during the recovery of very large doses, shown in Fig. 9.

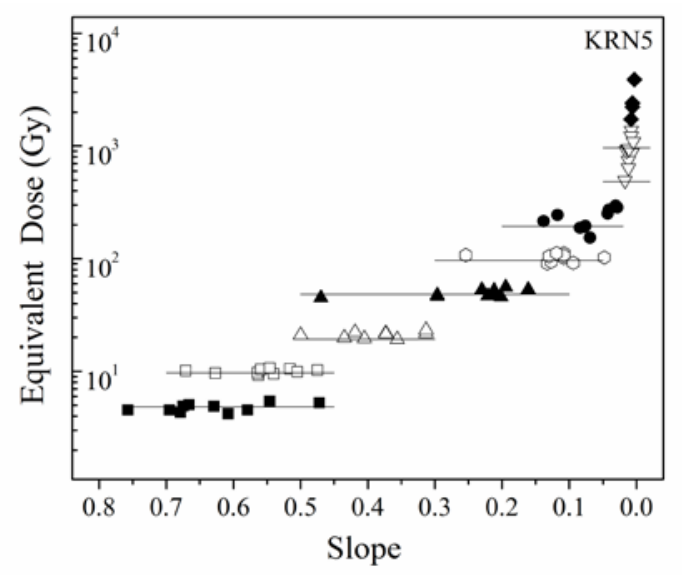

Fig. 9. Individual equivalent doses obtained in the dose recovery experiment plotted against their respective slopes. Straight lines represent the given dose. Note the logarithmic scale on Y-axis. 


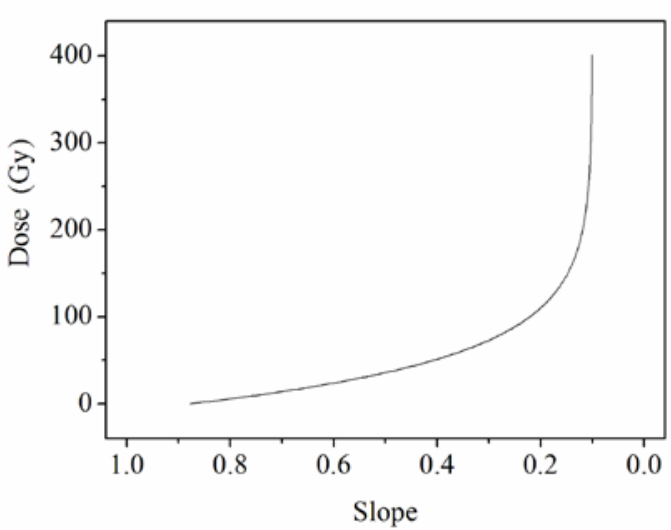

Fig. 10. Schematic expression of a differentiated growth curve, regenerated up to $400 \mathrm{~Gy}$, from one aliquot used at the $200 \mathrm{~Gy}$ dose recovery.

Strongly slope-depending equivalent doses stand as outliers and they cannot represent the sample. Be that as it may, when they intermix with a population of representative values (this is the case of 200 Gy in Fig. 9) will broaden and skew the distribution. This argumentation can explain similar observations made during the recovery of large doses discussed in section 3.5 as well as patterns of distribution described in Fig. 1 and Fig. 6a. counting these outliers in while averaging the dose will result both in overestimation and uncertainty. Thus, they must be excluded from any calculations. Fig. 6a has been recalculated by rejecting slope depending aliquots. The result is shown in Fig. 6b. Although no aliquot passed at doses greater than $500 \mathrm{~Gy}$, recalculated data at $200 \mathrm{~Gy}$ seem somewhat improved. The slight underestimation may be due to uncertainty induced by the restriction of the aliquot population.
The aforesaid rationale was tested on three representative natural samples; that used in the earlier dose recovery experiment and another couple from the same area. Only aliquots with successful recycling ratios were considered (1.1-0.9). All samples are assumed to originate from the Last Intrerglacial or further back in time. Fig. $11(\mathbf{a}, \mathbf{c}, \mathbf{e})$ demonstrates that a pattern in relationship between slope and asymmetry occurs in nature indeed. Whereas many $\mathrm{D}_{\mathrm{e}} \mathrm{s}$ tend to cluster, there others which eject to high doses when the slope becomes very small and constitute the tailing off part of the histograms. Supposing that our quartz received adequate bleaching before deposition and was buried in a homogeneously radiating environment, natural $\mathrm{D}_{\mathrm{e}} \mathrm{s}$ which exhibit strong dependence on the slope cannot represent the actual range of the palaeodose.

Attempts to exclude slope-depending $D_{\mathrm{e}} \mathrm{s}$ from computations would bring forth distributions which draw near the concept of normal. Plots b, d, f in Fig. 11 have been designed on that basis. At this earliest stage, cut-off slopes were roughly selected at the point where dispersion begins in slope/dose diagrams (under the horizontal dotted line). As expected, new distributions turned out to be tighter and more symmetric. Still, this process requires discarding $20-50 \%$ of the dataset. Therefore, these preliminary graphs are utilised to merely denote the tendency rather than to represent the actual range of the $D_{e}$. They need to populate with a larger number of individual estimates before they become acceptable for chronological applications. The efficacy of cut-off slopes as a criterion for reducing scatter is thereinafter contrasted to the measure suggested by Wintle and Murray (2006). Table 3 compares the average $D_{e}$ of PTC1 sample involved in Fig. 11 (a) before applying any condition (column 2) with the $\mathrm{D}_{\mathrm{e}}$ resulting from the application of the 'slopecriterion' and the ' $\mathrm{D}<2 \mathrm{D}_{\mathrm{o}}$ ' prerequisite (columns 5 and 7 respectively).

Table 3. Here each calculated $D_{e}$ per aliquot of PTC1 is tested by the 'slope' and ' $D<2 D_{0}$ ' criteria respectively. Only successful $D_{e} s$ have then been averaged accordingly. All doses are given in Grays.

\begin{tabular}{|c|c|c|c|c|c|c|}
\hline Aliquot & Initial $D_{e}$ & slope & cut-off slope & $\mathrm{D}_{\mathrm{e}}$ passing 'slope' & $2 D_{0}$ & $D_{e}$ passing ' $D<2 D_{0}$ ' \\
\hline 1 & 63.2 & 0.39 & \multirow{16}{*}{0.15} & 63.3 & 116.6 & 63.3 \\
\hline 2 & 54.2 & 0.35 & & 54.2 & 75.8 & 54.2 \\
\hline 3 & 66.0 & 0.34 & & 66.0 & 110.0 & 66.0 \\
\hline 4 & 71.1 & 0.30 & & 71.2 & 72.8 & 71.1 \\
\hline 5 & 67.7 & 0.30 & & 67.7 & 71.2 & 67.7 \\
\hline 6 & 63.7 & 0.26 & & 63.7 & 63.2 & - \\
\hline 7 & 84.2 & 0.25 & & 84.2 & 74.8 & - \\
\hline 8 & 70.0 & 0.22 & & 70.0 & 69.6 & - \\
\hline 9 & 82.0 & 0.20 & & 82.0 & 87.2 & 82.0 \\
\hline 10 & 87.3 & 0.19 & & 87.3 & 78.6 & - \\
\hline 11 & 98.3 & 0.18 & & 98.3 & 68.8 & - \\
\hline 12 & 81.4 & 0.17 & & 81.4 & 71.2 & - \\
\hline 13 & 99.3 & 0.11 & & - & 72.2 & - \\
\hline 14 & 112.6 & 0.08 & & - & 67.2 & - \\
\hline 15 & 119.5 & 0.07 & & - & 74.4 & - \\
\hline 16 & 156.9 & 0.06 & & - & 90.8 & - \\
\hline & $86.1 \pm 37 \%$ & & & $74.1 \pm 17 \%$ & & $67.4 \pm 13 \%$ \\
\hline
\end{tabular}



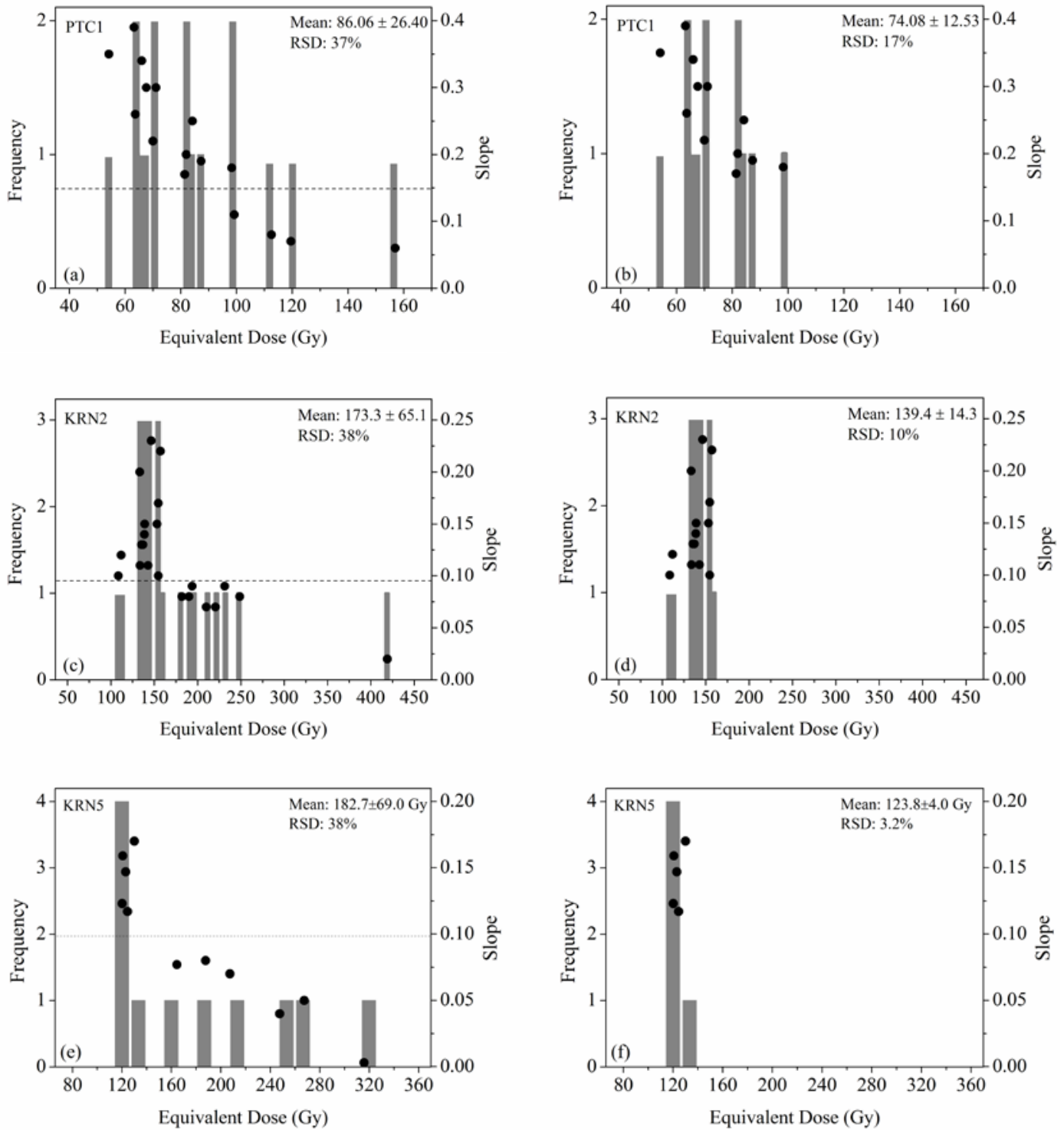

Fig. 11. Histograms revealing the distribution of apparent equivalent doses, from three naturally dosed samples, against their respective slopes at the

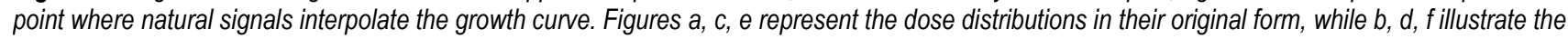
same distributions after applying the slope as a criterion for rejecting slope-dependant $D_{e}$ s. Dashed lines are used to roughly approximate the crucial slope threshold. Regenerated/test doses (in Gy) were allocated for the above samples as following. PTC1: 20,40,60,80,120,160/20; KRN2: 25,50,100,200,300,25/25; KRN5:20,40,80,120,200,280/20. Bin widths have been chosen as the median of the errors on each De (Lepper et al., 2000).

Although both norms can decrease the initial spread to a sizable degree, Wintle and Murray's (2006) check brings about more precisely constrained mean $\mathrm{D}_{\mathrm{e}} \mathrm{s}$ in samples exhibiting exponential plus linear OSL growth. Even so, it is noteworthy that the 'slope criterion' can approximate the performance of the ' $\mathrm{D}<2 \mathrm{D}_{\mathrm{o}}$ ' rule by $80 \%$.

Despite the fact that exclusion of slope depending aliquots improves the overall appearance of the dispersal, some scatter may still remain in the $D_{e}$ distributions. Several other causes of broadness in $\mathrm{D}_{\mathrm{e}}$ have been reported, which could act in excess of the slope dependency.
Lomax et al. (2007) bring together their results with other authors' observations and array a number of reasons which are potentially able to widen the range of $D_{e}$ in sediments. Discounting incomplete bleaching as root of extra variability, random errors sourcing from counting statistics in the measurement of luminescence as well as instrumental error can contribute to the remaining uncertainty by $1-8 \%$ (Duller, 2007; Lomax et al., 2007). Moreover, some amount of scatter can be credited to dosimetric causes. As noticed in Table 1, studied samples are characterized by a fairly low radionuclide content, indicating scarce distribution of the radioelements in the 
sediment. Those observations may disorder to some degree the original concept of a wholly homogenous radioactive field, making allowance for slightly uneven amounts of stored energy per quartz grain and therefore for slightly variable equivalent doses. Akin microdosimetric influences on equivalent dose distributions have been given accounts in other works (Murray and Roberts, 1997; Vandenberghe et al., 2003; Kalchgruber et al., 2003; Lomax et al., 2007). Post depositional influences such as increase of Radon emission due to diagenetic iron oxide staining on quartz grains (Vandenberghe et al., 2003), as well as intrusions of grains from other layers with different $\mathrm{D}_{\mathrm{e}} \mathrm{s}$ (Bateman et al., 2003) are likely to have happened and perturbed initially consistent equivalent doses. Those assumptions may stand adequate in explaining the remaining scatter but cannot be fully controlled by current means.

\section{CONCLUSIONS}

This paper summarises pilot applications of SAR on coastal quartz sediments from south Greece. The major obstacle was that these, otherwise well-bleached, samples experience both broadness and skeweness in the distribution of the equivalent dose, making the assessment of the latter uncertain. Standard tests on the validity of SAR proved that this material performs sufficiently the demands set by Murray and Wintle (2000). Thus, the cause of uncertainty in the equivalent dose estimation had to be investigated elsewhere.

Indeed, dose recovery experiments showed that a dose can be correctly restored when it remains lower than 100 Gy. This value may represent an average maximum, beyond which precision in the OSL chronology is doubtful for south Greece. A relationship between growth curve shape and spread in $\mathrm{D}_{\mathrm{e}}$ develops beyond $100 \mathrm{~Gy}$ though. Differential analysis proved that slope dependency of the dose is always present in non-linear growth curves. Close to saturation, growth curves are characterised by variable shapes and very small slope angles where the natural signal interpolates. These factors can overestimate the mean equivalent dose. These overestimated $\mathrm{D}_{\mathrm{e}} \mathrm{s}$ compose the tail which is seen in the distributions. Slope-depending values do not act for the sample and must be excluded. Comparable results stand for the naturally absorbed doses as well.

Slope, as an extra means of validation in SAR, could be useful only when it refers to standardised growth curves. Of course, simply discarding aliquots on visual basis is not very accurate, particularly when the population of single $D_{e}$ estimates is so small. Specifically, in Fig. 11f, so few aliquots passed the slope criterion that in fact the sample cannot be dated. However, the same graphs of Fig. 11 were able to demonstrate the general trend as well as that if a few of the outliers were removed higher accuracy in the mean $D_{e}$ could be achieved. Perhaps a routine procedure based on that motif could be designed and applied on large aliquot groups, aiming to reduce the scatter in the equivalent dose distributions for samples which lay close to saturation. In addition, although Wintle and Murray's (2006) necessity for equivalent doses smaller than twice the characteristic dose has a better control on the scatter, slope as a criterion for reliability was in good agreement with these authors requirement.

\section{ACKNOWLEDGEMENTS}

C.A. is thankful to Professor Geoff Duller and the Aberystwyth Luminescence Research Laboratory (Aberystwyth University, Wales). Professor Reuven Chen and two anonymous reviewers are also acknowledged.

\section{REFERENCES}

Adamiec G and Aitken MJ, 1998. Dose-rate conversion factors: update. Ancient TL 16: 37-50.

Armitage SJ, Duller GAT and Wintle AG, 2000. Quartz from southern Africa: sensitivity changes as a result of thermal pretreatment. $R a-$ diation Measurements 32(5-6): 571-577, DOI 10.1016/S13504487(00)00053-6.

Bateman MD, Frederick CD, Jaiswal MK and Singhvi AK, 2003. Investigations into the potential effects of pedoturbation on luminescence dating. Quaternary Science Reviews 22(10-13): 11691176, DOI 10.1016/S0277-3791(03)00019-2.

Duller GAT, 2001. Analyst manual: 36pp.

Duller GAT, 2007. Assessing the error on equivalent dose estimates derived from single aliquot regenerative dose measurements. $A n$ cient TL 25: 15-24.

Jacobs Z, Wintle AG and Duller GAT, 2006. Evaluation of SAR procedures for $D$ e determination using single aliquots of quartz from two archaeological sites in South Africa. Radiation Measurements 41(5): 520-533, DOI 10.1016/j.radmeas.2005.10.008.

Kalchgruber R, Fuchs M, Murray AS and Wagner GA, 2003. Evaluating dose-rate distributions in natural sediments using $\alpha-\mathrm{Al}_{2} \mathrm{O}_{3}$ : C grains. Radiation Measurements 37(4-5): 293-297, DOI 10.1016/S1350-4487(03)00012-X.

Kim JC, Duller GAT, Roberts HM, Wintle AG, Lee YI and Yi SB, 2010. Re-evaluation of the chronology of the palaeolithic site at Jeongokri, Korea, using OSL and TT-OSL signals from quartz. Quaternary Geochronology 5(2-3): 365-370, DOI 10.1016/j.quageo.2009.02.005.

Lepper K, Larsen NA and McKeever SWS, 2000. Equivalent dose distribution analysis of Holocene eolian and fuvial quartz sands from Central Oklahoma. Radiation Measurements 32(5-6): 603608, DOI 10.1016/S1350-4487(00)00093-7.

Lomax J, Hilgers A, Twidale CR, Bourne JA and Radtke U, 2007. Treatment of broad palaeodose distributions in OSL dating of dune sands from the western Murray Basin, South Australia. Quaternary Geochronology 2(1-4): 51-56, $\quad$ DOI 10.1016/j.quageo.2006.05.015.

Murray AS and Funder S, 2003. Optically stimulated luminescence dating of a Danish Eemian coastal marine deposit: a test of accuracy. Quaternary Science Reviews 22(10-13): 1177-1183, DOI 10.1016/S0277-3791(03)00048-9.

Murray AS and Olley JM, 2002. Precision and accuracy in the optically stimulated luminescence dating of sedimentary quartz: A status review. Geochronometria 21: 1-16.

Murray AS and Roberts RG, 1997. Determining the burial time of single grains of quartz using optically stimulated luminescence. Earth and Planetary Science Letters 152(1-4): 163-180, DOI 10.1016/S0012-821X(97)00150-7.

Murray AS and Wintle AG, 2000. Luminescence dating of quartz using an improved single - aliquot regenerative - dose protocol. Radia- 
tion Measurements 32(1): 57-73, DOI $10.1016 / \mathrm{S} 1350$ 4487(99)00253-X.

Murray AS, Wintle AG and Wallinga J, 2002. Dose estimation using quartz OSL in the non-linear region of the growth curve. Radiation Protection Dosimetry 101(1-4): 371-374.

Murray AS, Buylaert JP, Henriksen M, Svendsen JI and Mangerud J, 2008. Testing the reliability of quartz OSL ages beyond the Eemian. Radiation Measurements 43(2-6): 776-780, DOI 10.1016/j.radmeas.2008.01.014.

Paepe R, Mariolakos I, Van Overloop E and Keppens E, 1990. Last Interglacial-glacial north - south geosoil traverse (from stratotypes in the North Sea Basin and in the Eastern Mediterranean). Quaternary International 5: 57-70, DOI 10.1016/1040-6182(90)90025-Y.

Roberts HM and Duller GAT, 2004. Standardised growth curves for optical dating of sediment using multiple-grain aliquots. Radiation
Measurements $\quad 38(2)$ :

241-252,

DOI

10.1016/j.radmeas.2003.10.001.

Singhvi AK, Bluszcz A, Batema, MD and Someshwar Rao M, 2001. Luminescence dating of loess-palaeosol sequences and coversands: methodological aspects and palaeoclimatic implications. Earth Science Reviews 54(1-3): 193-211, DOI 10.1016/S00128252(01)00048-4.

Vandenberghe D, Hossain SM, De Corte F and Van den haute P, 2003. Investigation on the origin of the equivalent dose distribution in a Dutch coversand. Radiation Measurements 37(4-5): 433-439, DOI 10.1016/S1350-4487(03)00051-9.

Wintle AG and Murray AS, 2006. A review of quartz optically stimulated luminescence characteristics and their relevance in singlealiquot regeneration dating protocols. Radiation Measurements 41(4): 369-391, DOI 10.1016/j.radmeas.2005.11.001. 